\title{
Pelatihan Teknik Hidroponik untuk Mengatasi Lahan Berkadar Garam Tinggi pada Masyarakat Pesisir Gampong, Kuala Langsa, Aceh
}

\author{
Vivi Mardina ${ }^{1}$, Yulida Amri²*, Tisna Harmawan² \\ ${ }^{1}$ Program Studi Biologi, Fakultas Teknik, Universitas Samudra, Langsa Lama, Langsa, Aceh, Indonesia \\ ${ }^{2}$ Program Studi Kimia, Fakultas Teknik, Universitas Samudra, Langsa Lama, Langsa, Aceh, Indonesia
}

Submisi: 21 Oktober 2018 ; Revisi: 28 Januari 2020; Penerimaan: 10 februari 2020

Kata Kunci: Abstrak Gampong Kuala Langsa merupakan salah satu desa yang terletak di

Hidroponik

Lahan terbatas

Metode apung

NFT

Salinitas tanah pesisir Kecamatan Langsa Barat, Langsa, Aceh. Secara geografis, Gampong terletak di dataran rendah sehingga menyebabkan terjadinya pasang naik air laut. Akibatnya tanah di Gampong Kuala Langsa memiliki tingkat salinitas tinggi, yakni sekitar 28,3-36 ppm. Kondisi tanah tersebut sangat tidak menguntungkan untuk bercocok tanam sayuran. Selain keadaan tanah yang tidak menguntungkan, terbatasnya lahan yang tersedia (dialihfungsikan sebagai tambak dan hutan mangrove) menjadi permasalahan mitra dalam memenuhi kebutuhan sayuran secara mandiri. Solusi permasalahan tersebut adalah dengan melakukan pengenalan dan penerapan sistem bercocok tanam secara hidroponik karena sistem ini sangat cocok diterapkan di daerah dengan kondisi tanah yang memiliki salinitas tinggi dan lahan terbatas. Bentuk kegiatan pengabdian ini adalah pelatihan yang terdiri atas tiga tahapan utama, yaitu survei lokasi dan sosialisasi, pelatihan, dan pemonitoran/evaluasi. Berdasarkan hasil kegiatan dapat disimpulkan bahwa (a) pengetahuan masyarakat mengenai teknik hidroponik meningkat yang ditandai dengan respons positif; (b) bercocok tanam secara hidroponik menggunakan metode nutrient film technique (NFT) dan metode rakit apung (metode sederhana) berhasil dilaksanakan oleh ibu-ibu PKK; dan (c) kegiatan ini sangat bermanfaat bagi masyarakat Gampong Kuala Langsa, khususnya ibu-ibu PKK sebagai sarana pendidikan kemandirian pangan.

Keywords:

Abstract Gampong Kuala Langsa is one of the villages located on the coast of Floating method Hydroponics Langsa Barat District, Langsa, Aceh. Geographically, this village is located in the Limited land NFT lowlands which causes rising tides of seawater. As a consequence, the land in Kuala Langsa has a high level of salinity about 28,3-36 ppm. The condition of the soil is very unfavorable for growing vegetables. Besides the unfavorable land Soil salinity conditions, the limited available land due to conversion for ponds and mangrove plantations also poses a challenge in fulfilling the need for vegetables independently. The solution to these problems is by introducing and applying hydroponic farming systems because this system is very suitable to be applied in areas with high salinity soil conditions and limited areas of land. The method of this activity is training which consists of three main stages, namely survey of the location and socialization, training, and monitoring/evaluation. The results of the activity concluded that (a) hydroponic knowledge of the community of Gampong Kuala Langsa increased which was assigned by a positive response; (b) hydroponic farming using the nutrient film technique (NFT) method and the floating raft method (simple method) successfully carried out by PKK members; and (c) this activity is very beneficial for the Gampong Kuala Langsa community, particularly for PKK members as a means to educate food independence.

ISSN 2460-9447 (print), ISSN 2541-5883 (online)

${ }^{*}$ Corresponding author: Yulida Amri

Program Studi Kimia, Fakultas Teknik, Universitas Samudra, Jln. Prof. Dr. Syarief Thayeb Meurandeh, Langsa Lama, Langsa, Aceh, Indonesia Email:amri.rumia@gmail.com 


\section{PENDAHULUAN}

Gampong Kuala Langsa yang merupakan salah satu desa di Kecamatan Langsa Barat, Kota Langsa, Aceh memiliki potensi utama pada sektor pariwisata dan perikanan. Secara geografis, Kuala Langsa terletak antara $4^{\circ} 29^{\prime} 48.5^{\prime \prime}-4^{\circ} 32^{\prime} 49.0^{\prime \prime}$ lintang utara dan 97'59'45.7"98 $02^{\prime} 19.7^{\prime \prime}$ bujur timur. Berdasarkan data dari Badan Pusat Statistik (BPS) Kota Langsa 2010 dan 2019 diketahui bahwa Gampong Kuala Langsa memiliki wilayah terluas, yakni $20,02 \mathrm{~km}^{2}$ dari total luas wilayah Langsa Barat $\left(59.95 \mathrm{~km}^{2}\right)$ dengan jumlah penduduk mencapai 35.901 jiwa pada 2018 atau sekitar 33,39 persen dari luas wilayah Langsa Barat yang terdiri atas ¥497 kepala keluarga (BPS Kota Langsa, 2019).

Secara administrasi, Kecamatan Langsa Barat berada di wilayah utara-tengah yang berbatasan langsung dengan Selat Malaka di sebelah utara, berbatasan dengan Kecamatan Langsa Kota di sebelah selatan, berbatasan dengan Kecamatan Langsa Baro di sebelah timur, dan berbatasan dengan Langsa Timur di sebelah barat (BPS Kota Langsa, 2019). Adapun topografi permukaan daratan Kecamatan Langsa Barat relatif datar, tanpa perbukitan, dan elevasi 0-8 mdpl (Gambar 1) (Fadhli, 2011).

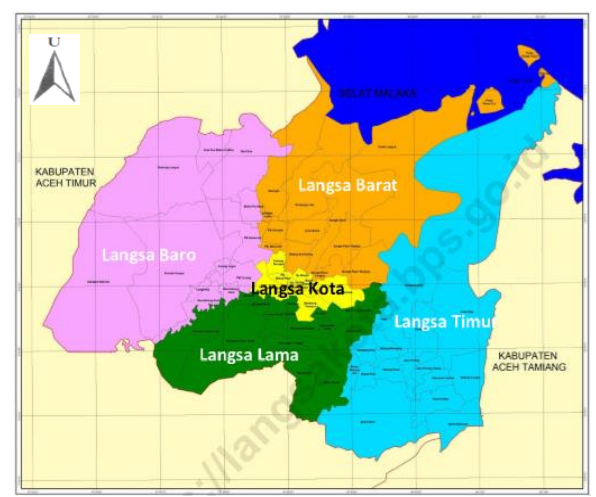

Keterangan :

Laut

Langsa Barat

Langsa Baro

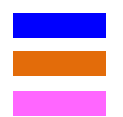

Langsa Kota

Langsa Lama

Langsa Timur

Gambar 1. Peta lokasi kegiatan (Skala 1:35.000). Sumber: BPS Kota Langsa (2019)

Kondisi geografis desa Gampong Kuala Langsa yang berada di dataran rendah mengakibatkan keadaan tanah menjadi memiliki salinitas tinggi, yaitu berkisar antara 28,3-36 ppm (Tumangger \& Fitriani, 2019). Keadaan tanah yang memiliki salinitas tinggi dapat menyebabkan terganggunya perkecambahan dan pembentukan bibit serta terhambatnya pertumbuhan dan produktivitas tanaman secara umum. Jumlah garam yang tinggi pada tanah mengakibatkan potensial osmotik menurun sehingga tanaman sulit menyerap air (mengalami kekeringan fisiologis). Kekeringan fisiologis berdampak pada terhambatnya penyerapan beberapa unsur hara yang berada dalam bentuk ion terlarut dalam air sehingga berakibat buruk pada pertumbuhan tanaman (Satya et al., 2017; Syakir et al., 2008).

Hidroponik merupakan teknik budi daya tanaman tanpa media tanam berupa tanah, tetapi memanfaatkan air sebagai media tanam (Putri et al., 2017; Roidah, 2014). Pelatihan dan penerapan teknik bercocok tanam dengan sistem hidroponik bagi masyarakat Gampong Kuala Langsa sangat efektif dilakukan untuk mengatasi masalah tanah yang bergaram tinggi dan lahan yang terbatas. Keuntungan teknik hidroponik adalah (a) tidak memerlukan tanah sebagai media tanam; (b) perawatan tanaman lebih mudah; (c) dapat menghemat pupuk dan air; serta (d) dapat mengatasi masalah lahan yang terbatas (Mardina et al., 2019) dan kondisi tanah yang tidak menguntungkan (Kaunang et al., 2016).

Adapun jenis sistem hidroponik sangat beragam, seperti sistem irigasi tetes, wick system, sistem nutrient film technique (NFT), dan sistem rakit apung (Herwibowo \& Budiana, 2014; Hendra \& Andoko, 2014). Keanekaragaman sistem hidroponik mengacu pada dua prinsip dasar hidroponik, yakni wick system dan NFT (Roidah, 2014). Sistem NFT merupakan model dalam sistem hidroponik, yakni akar tanaman ditempatkan pada lapisan air atau media bernutrisi yang dangkal (Gambar 2). Media air disirkulasikan sehingga tanaman memperoleh nutrisi dan oksigen yang cukup. Biasanya sistem NFT pada metode hidroponik dibuat dengan tinggi maksimal larutan $3 \mathrm{~mm}$ (Roidah, 2014).

Berbeda dengan sistem NFT, metode rakit apung (floating hydroponic system) menggunakan prinsip tanaman yang ditanam dalam keadaan terapung, yakni tepat di atas nutrisi (media air bernutrisi tidak dialirkan seperti pada sistem NFT). Keuntungan utama sistem NFT adalah akar tanaman mendapatkan air, oksigen, dan nutrisi yang cukup sehingga pertumbuhan tanaman dengan sistem ini lebih cepat daripada sistem hidroponik lainnya (Rangian et al., 2017; Roidah, 2014). Kelemahan sistem NFT adalah gangguan aliran jika terjadi pemadaman listrik.

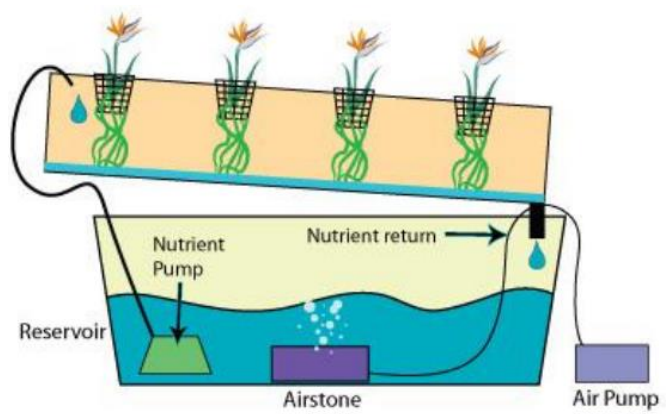

Gambar 2. Prinsip dasar nutrient film technique(NFT). Sumber: Roidah (2014)

Metode rakit apung disebut juga raft system atau water culture system (Roidah, 2014; Rangian et al., 2017). Pada kegiatan pengabdian ini, metode rakit apung dikombinasikan dengan metode wick system atau teknik 
sumbu, yaitu memanfaatkan gaya kapilaritas pada sumbu untuk mengantarkan air dan nutrisi ke akar tanaman sehingga akar dapat menyerap unsur-unsur hara yang disediakan (Rangian et al., 2017).

Hidroponik wick system atau teknik sumbu sangat tepat digunakan oleh pemula yang ingin bertanam sayuran secara hidroponik karena prinsipnya yang mudah dan sederhana (hanya memanfaatkan kapilaritas air). Selain itu, hidroponik wick system mudah dirakit, tidak memerlukan perawatan khusus, portabel (dapat dipindahkan), dan sangat cocok diterapkan di lahan terbatas atau pada kondisi tanah yang bersalinitas tinggi (Hendra \& Andoko, 2014; Herwibowo \& Budiana, 2014; Rangian et al., 2017).

Kondisi geografis Gampong Kuala Langsa yang terletak di dataran rendah atau pesisir pantai menjadi pendorong utama bagi penduduk untuk bekerja sebagai nelayan dan petani tambak (BPS Kota Langsa, 2013). Di sisi lain, kondisi geografis desa yang berada di dataran rendah mengakibatkan keadaan tanah menjadi memiliki salinitas tinggi, yaitu berkadar garam tinggi (28,3-36 ppm) (Tumangger \& Fitriani, 2019). Keadaan tanah tersebut sangat tidak menguntungkan untuk bercocok tanam sayuran. Akibatnya masyarakat Gampong Kuala Langsa tidak dapat memenuhi kebutuhan sayurannya secara mandiri.

Kebutuhan sayuran masyarakat Gampong Kuala Langsa biasanya dipenuhi dengan membeli di toko sayuran yang berada di Gampong Kuala Langsa, yaitu UD Bunda. UD Bunda membeli sayur-sayuran di Pasar Kota Langsa yang jaraknya sekitar $8 \mathrm{~km}$ dari desa. Hal itu menambah biaya pengeluaran dan tidak efisien dari segi waktu. Hal lain yang menyebabkan masyarakat Gampong Kuala Langsa tidak dapat secara mandiri memenuhi kebutuhan sayuran adalah terbatasnya lahan yang tersedia. Lahan luas yang semula tersedia telah dialihfungsikan sebagai tambak dan hutan mangrove. Kuala Langsa (Kecamatan Langsa Barat) memiliki areal tambak seluas \pm 843 ha dan hutan mangrove seluas 7837 ha (BPS Kota Langsa, 2019). Selain itu, rumah warga di Kuala Langsa tidak memiliki pekarangan karena dibangun di atas air pasang (terapung) (Gambar 3).

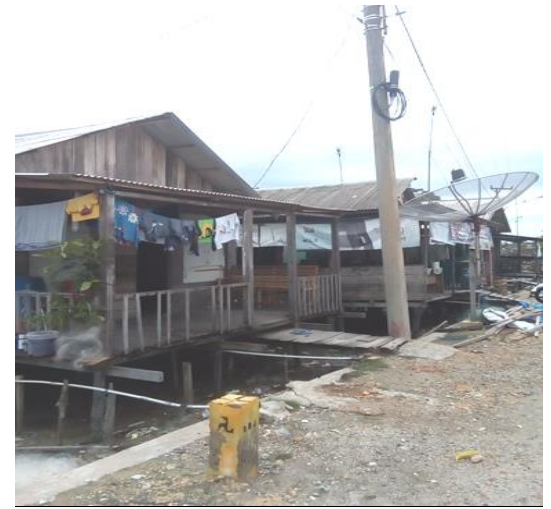

Gambar 3. Keadaan perumahan penduduk di Gampong Kuala Langsa

Minimnya pengetahuan masyarakat mengenai teknik bercocok tanam alternatif tanpa menggunakan media tanah pada lahan yang tidak mendukung (salinitas tinggi) menjadi permasalahan dasar pada masyarakat Gampong Kuala Langsa, Aceh. Keadaan tanah yang memiliki salinitas tinggi merupakan ciri tanah di sekitar pantai (pasir pantai) yang mengikat dan menyediakan air dan unsur hara dalam jumlah yang rendah sehingga tergolong tanah dengan produktivitas rendah (Satya et al., 2017).

Masalah lain yang dihadapi masyarakat Gampong Kuala Langsa, Aceh adalah terbatasnya lahan untuk bercocok tanam sayuran karena sebagian besar difungsikan sebagai tambak dan hutan mangrove (Gambar 4). Oleh karena itu, pengetahuan mengenai teknik bertanam sayur alternatif (hidroponik) sangat diperlukan untuk memecahkan masalah tersebut, seperti menghasilkan produk berupa sayuran dalam skala rumah tangga dengan memanfaatkan pekarangan rumah yang terbatas karena faktor keadaan tanah dan diharapkan dapat dipasarkan (bernilai ekonomis).

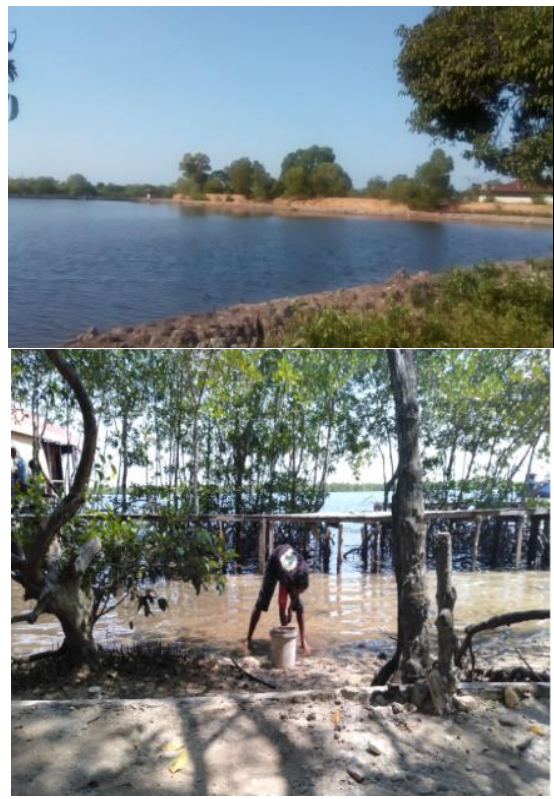

Gambar 4. Lahan Kuala Langsa yang dialihfungsikan menjadi tambak dan hutan mangrove

Berdasarkan permasalahan di atas, tujuan utama kegiatan pengabdian ini adalah untuk memberi pelatihan dan mengajak masyarakat Gampong Kuala Langsa untuk secara langsung menerapkan sistem hidroponik sehingga diharapkan mereka dapat memenuhi kebutuhan sayuran secara mandiri.

\section{METODE}

Kegiatan pengabdian ini dilaksanakan pada 20 Agustus hingga 7 Oktober 2018 di Gampong Kuala Langsa, Kecamatan Langsa Barat, Aceh dengan target utama ibu- 
ibu PKK. Lokasi pelaksanaan di Balai Desa Gampong Kuala Langsa, Kecamatan Langsa Barat Kota Langsa. Pelatihan diikuti oleh 38 peserta yang terdiri atas $20 \mathrm{ibu}$ PKK Gampong Kuala Langsa, 5 orang dosen, dan 13 orang mahasiswa.

Kegiatan pengabdian ini dilaksanakan dalam tiga tahap yaitu, (a) survei lokasi dan sosialisasi; (b) pelaksanaan pelatihan (praktik lapangan); dan (c) pemonitoran/evaluasi. Pada tahap survei lokasi dan sosialisasi, tim pengabdian kepada masyarakat (PKM) melakukan observasi, pendataan awal, dan menyosialisasikan program pelatihan hidroponik yang dimulai pada 3 September-30 September 2018. Pada kegiatan pengabdian ini, tim PKM mengombinasikan wick system dan NFT serta mengadopsi sistem rakit apung dengan media tanam rockwool.

Materi sosialisasi meliputi (a) prinsip dasar dan keuntungan bertanam secara hidroponik; (b) sistem hidroponik dengan metode nutrient film technique (NFT) dan rakit apung (metode hidroponik sederhana dan murah); (c) sistem alir dan tidak alir; dan (d) serta cara menanam dengan sistem hidroponik (Gambar 5 dan 6). Sosialisasi dilakukan dengan metode ceramah, diskusi, dan tanya jawab serta menggunakan power point sehingga lebih menarik. Tim PKM juga memberikan panduan bercocok tanam hidroponik kepada peserta sebagai pedoman. Kegiatan tahap kedua adalah pelatihan yang meliputi praktik langsung tentang (a) teknik pembuatan nutrisi sederhana; (b) pembibitan dan penyemaian; (c) sistem alir dan tidak alir; serta (d) perawatan tanaman.

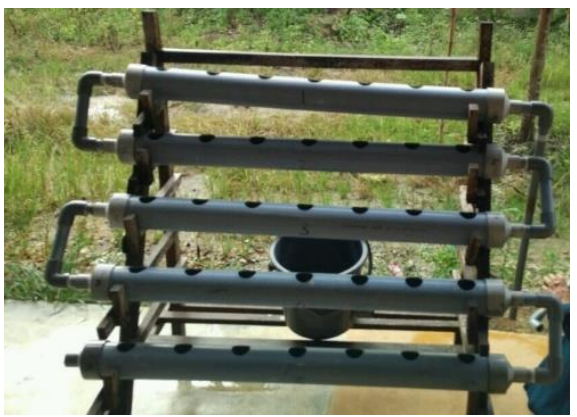

Gambar 5. Rancang bangun nutrient film technique (NFT) untuk Budi Daya Sayuran Hidroponik

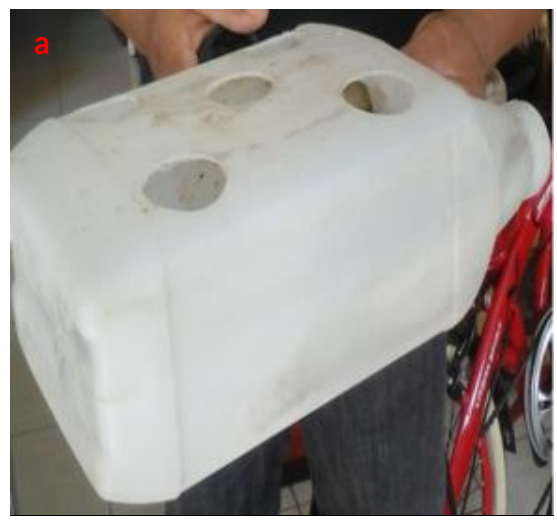

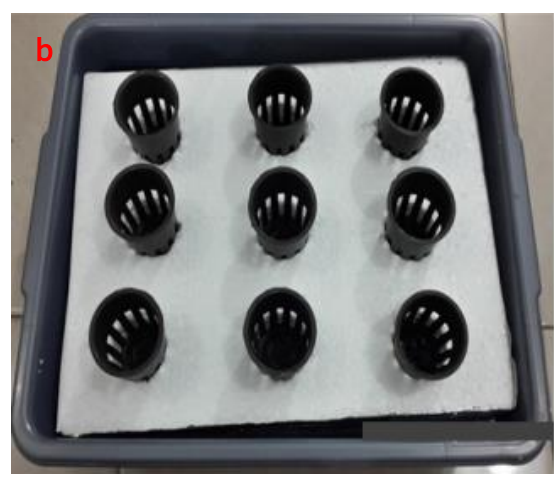

Gambar 6. Teknik hidroponik rakit apung menggunakan wadah bekas berbahan dasar (a) plastik dan (b) stirofoam

Tahap terakhir kegiatan pengabdian ini adalah pemonitoran dan evaluasi kegiatan. Kegiatan ini bertujuan untuk memastikan bahwa semua prosedur berjalan dengan benar sehingga tujuan program benarbenar terealisasi. Adapun evaluasi secara kualitatif untuk keberhasilan pelaksanaan program PKM dilakukan melalui kuesioner yang diberikan pada peserta sebelum dan sesudah pelaksanaan kegiatan sebagaimana disarankan oleh Mardina et al. (2019). Kuesioner tersebut meliputi pemahaman materi pelatihan dan penerapan materi yang telah diberikan selama proses kegiatan berlangsung, rintangan yang dihadapi selama praktik lapangan, dan dampak manfaat dari pelatihan menanam sayuran dengan sistem hidroponik. Pada tahap pemonitoran juga dilakukan tahap pendampingan untuk mengatasi kendala atau permasalahan yang mungkin dihadapi oleh masyarakat ketika merawat tanaman hidroponik.

\section{HASIL DAN PEMBAHASAN}

\subsection{Survei lokasi dan sosialisasi}

Survei lokasi merupakan tahap awal dari rangkaian kegiatan pengabdian kepada masyarakat yang bertujuan untuk mengobservasi serta memastikan lokasi pelaksanaan dan target sasaran kegiatan. Berdasarkan hasil survei lokasi dan diskusi bersama dengan perangkat desa, balai desa yang berada tepat di belakang kantor Geuchik (kepala desa) Gampong Kuala Langsa dijadikan sebagai tempat sosialisasi dan pelaksanaan pelatihan.

Pada tahap sosialisasi, peserta diberi materi mengenai teknik hidroponik, contoh tanaman hidroponik, media hidroponik, cara menanam serta menyemai benih hidroponik, dan cara memberi serta menyiapkan nutrisi hidroponik. Sosialisasi dilakukan oleh tim PKM melalui presentasi menggunakan media powerpoint.

Penyemaian bibit dilakukan pada nampan plastik dengan media tanam rockwool. Rockwool yang berukuran $\pm 2,5 \times 2,5 \mathrm{~cm}$ dipotong dadu lalu dibasahi dan dilubangi tengahnya sedikit dengan tusuk gigi. Pada lubang media yang telah dibuat kemudian diletakkan satu bibit dan dibiarkan berkecambah pada ruang gelap 
selama 24 jam (umumnya untuk tanaman tidak berkambium, seperti kangkung dan sawi) (Gambar 7). Adapun tanaman, seperti cabai dan tomat membutuhkan waktu 1-3 hari. Hasil perkecambahan kemudian diletakkan di ruangan yang terkena sinar matahari (teras rumah) dan disiram setiap hari hingga tumbuh daun sejati (daun tiga helai). Bibit yang telah tumbuh daun sejati dipindahkan ke sistem hidroponik (umumnya membutuhkan 5-7 hari) (Mardina et al., 2019).
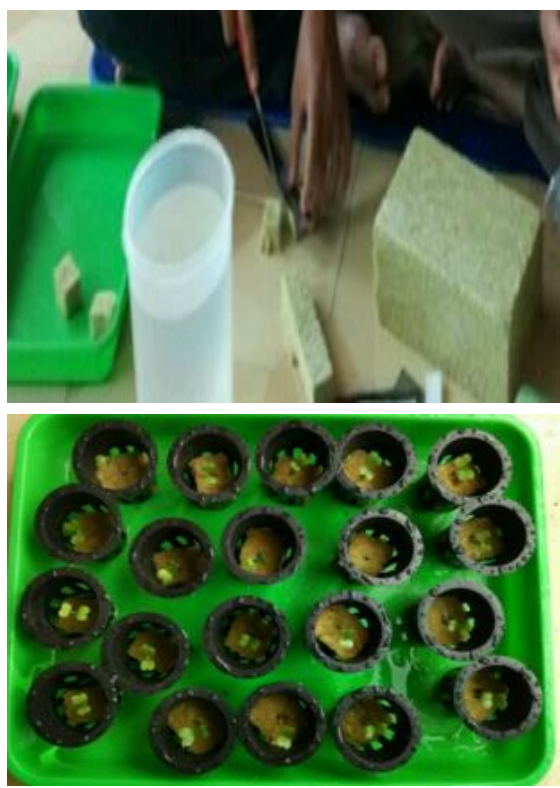

Gambar 7. Proses Penyemaian Bibit pada Media Rockwool

Semua peserta dalam kegiatan ini juga diberi panduan mengenai cara bertanam hidroponik sehingga diharapkan dapat memahami teknik hidroponik dengan baik. Pada tahap sosialisasi, masyarakat mengikuti kegiatan dengan sangat antusias. Hal itu ditandai dengan adanya tanya jawab yang menunjukkan bahwa masyarakat memiliki rasa ingin tahu yang tinggi terhadap materi yang disampaikan.

\subsection{Pelatihan}

Tahap selanjutnya adalah pelatihan dan penerapan teknik menanam sayur secara hidroponik. Pelatihan dilakukan untuk mengajak peserta mempraktikkan langsung materi yang telah disampaikan pada tahap sosialisasi, yakni penyiapan media rockwool, penyemaian bibit, pemindahan bibit dari rockwool ke sistem tanam hidroponik, penyiapan nutrisi, dan pengemasan sayur (teknik pengemasan menggunakan stirofoam dan plastik wrapping). Bibit sayuran yang disemai adalah selada, sawi, dan kangkung. Bibit yang telah dibiarkan tumbuh selama lebih kurang satu minggu dipindahkan ke sistem tanam hidroponik (sistem NFT dan rakit apung) yang telah diisi larutan nutrisi. Larutan nutrisi yang digunakan adalah AB mix dengan konsentrasi \pm 1300 ppm (volume stok masing-masing 2,5 1) (Gambar 8).

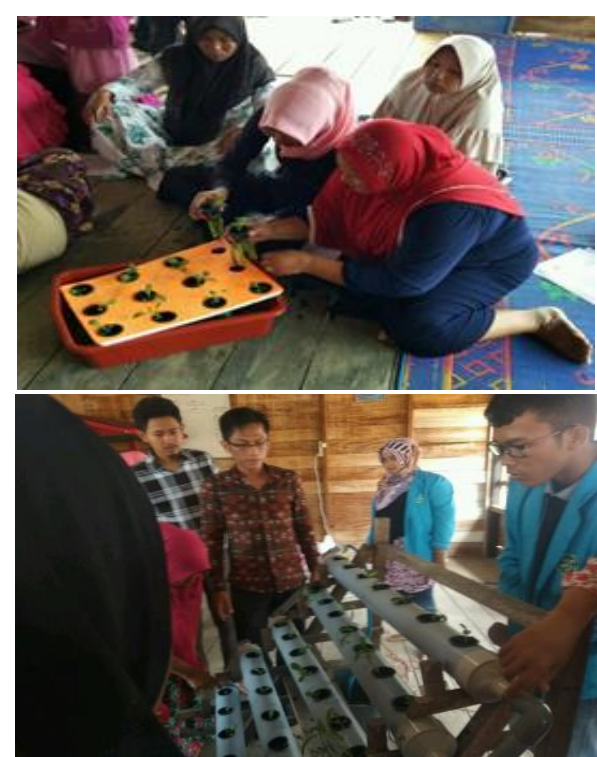

Gambar 8. Peserta dilatih bertanam sayur secara hidroponik

Selain air, beberapa media tanam yang dapat digunakan adalah rockwool, coconut coir/ coco peat, perlite, lightweight expanded clay aggregate (LECA), pasir, wood fiber, gravel (kerikil), brick shards (pecahan kerikil), ampas tebu, arang sekam atau zeolite, gambut (peat mass), ampas tebu atau serabut kelapa (Kaunang et al., 2016; Bachtiar et al., 2017; Efriyadi, 2018; Mardina et al., 2019). Penggunaan sistem sumbu (wick system ) oleh tim PKM juga bertujuan untuk mengantisipasi jika akar tanaman terlalu pendek sehingga tidak masuk secara sempurna ke dalam nutrisi. Jika hal itu terjadi, pertumbuhan tanaman akan terganggu karena nutrisi tidak terserap dengan baik. Pada kegiatan pengabdian ini, tim PKM juga menggunakan dan memperkenalkan sistem NFT yang dikombinasikan dengan sistem sumbu. NFT merupakan model budi daya dengan meletakkan akar tanaman pada lapisan air (nutrien) yang tipis $( \pm 3$ $\mathrm{cm})$ sebagai medianya. Agar terbentuk selapis larutan nutrisi yang menggenangi perakaran biasanya digunakan wadah penanaman, seperti talang air atau pipa PVC yang diletakkan pada kemiringan tertentu. Larutan nutrisi dialirkan dari bak penampungan dengan pompa yang digerakkan oleh energi listrik. Karena adanya aliran nutrisi menggunakan pompa, sistem ini juga disebut sistem alir.

Praktik penyiapan nutrisi juga diajarkan karena nutrisi menunjang pertumbuhan tanaman, selain kecukupan sinar matahari dan terhindar dari hujan agar nutrisi tetap terjaga. Jenis nutrisi yang diperkenalkan kepada peserta adalah $\mathrm{AB}$ mix daun komersil. Nutrisi AB mix terdiri atas dua jenis, yaitu nutrisi A dan nutrisi B yang keduanya berbentuk padatan serbuk. Nutrisi A umumnya mengandung kalsium amonium nitrat, kalium nitrat, dan Fe-EDTA. Adapun nutrisi B berisi kalium dihidro sulfat, amonium sulfat, magnesium sulfat, magan sulfat, tembaga sulfat, seng sulfat, asam borat, dan amonium molibdat (Sastro \& Rokhmah, 2016). Pada 
kegiatan ini, satu pack/bungkus nutrisi A dan B masingmasing dilarutkan dalam $2500 \mathrm{ml}$ air. Setiap 1 liter air sebagai media nutrisi hidroponik ditambah dengan $5 \mathrm{ml}$ nutrisi A dan $5 \mathrm{ml}$ nutrisi B. Media air nutrisi hidroponik ditambahkan seminggu sekali sebanyak \pm 1 liter.

Sistem hidroponik berikutnya yang diperkenalkan kepada peserta adalah sistem rakit apung (floating raft atau water culture system) menggunakan wadah stirofoam dan nampan. Jeriken atau botol air mineral bekas juga dapat digunakan (Gambar terlampir). Sistem ini sangat sederhana karena tidak memerlukan peralatan canggih (Zuhaida et al., 2012). Akan tetapi, dalam sistem ini diperlukan aerator (sebaiknya) untuk pertukaran oksigen tanaman dan media tanam hanya dapat ditumbuhi oleh tumbuhan berbobot rendah (Rangian et al., 2017). Dua hal tersebut menjadi kelemahan sistem rakit apung.

\subsection{Pemonitoran dan evaluasi}

Pemonitoran dan evaluasi dilakukan setelah pelaksanaan pelatihan. Pada tahap ini, pemahaman peserta mengenai pelatihan yang telah dilaksanakan diukur secara kualitatif dengan kuesioner berdasarkan gagasan dari Mardina et al. (2019) dan Surtinah et al. (2017). Adapun hasilnya ditunjukkan pada Tabel 1.

Tabel 1. Tanggapan masyarakat perihal pelatihan hidroponik

\begin{tabular}{clcccc}
\hline & & \multicolumn{4}{c}{ Pelatihan (\%) } \\
\cline { 2 - 5 } No. Komponen & \multicolumn{2}{c}{ Sebelum } & \multicolumn{3}{c}{ Setelah } \\
\cline { 2 - 5 } & Ya & Tidak & Ya & Tidak \\
\hline 1. $\begin{array}{l}\text { Mengetahui istilah } \\
\text { hidroponik }\end{array}$ & 10 & 90 & 100 & 0 \\
2. $\begin{array}{l}\text { Berminat menanam } \\
\text { secara hidroponik }\end{array}$ & 95 & 5 & 100 & 0 \\
3. $\begin{array}{l}\text { Memahami budi daya } \\
\text { hidroponik dengan } \\
\text { baik }\end{array}$ & 0 & 100 & 100 & 0 \\
4. $\begin{array}{l}\text { Memahami cara } \\
\text { perawatan dan } \\
\text { pemberian nutrisi }\end{array}$ & 5 & 95 & 90 & 10 \\
Kegiatan pengabdian & 100 & 0 & 100 & 0 \\
& $\begin{array}{l}\text { bermanfaat bagi } \\
\text { masyarakat }\end{array}$ & & & & \\
\hline
\end{tabular}

Berdasarkan tabel 1 di atas dapat dilihat bahwa (a) kegiatan pengabdian tentang teknik bertanam sayur secara hidroponik sangat bermanfaat bagi peserta, yakni masyarakat Gampong Kuala Langsa, Aceh; (b) meningkatkan minat masyarakat untuk bertanam sayur sehingga mengatasi permasalahan kondisi tanah bersalinitas dan pekarangan terbatas; (c) berpotensi menciptakan kemandirian pangan serta dapat ditingkatkan menjadi skala bisnis; dan (d) meningkatkan perekonomian serta kesehatan masyarakat sebagai efek jangka panjang.

Pada tahap pemonitoran dan evaluasi, tim PKM Universitas Samudra menyerahkan seperangkat alat hidroponik. Program pendampingan dijadwalkan sesuai fase pertumbuhan tanaman. Komunikasi dengan Geuchik
Kuala Langsa dan ketua PKK tetap dijalin melalui hubungan telekomunikasi.

\section{KESIMPULAN}

Kegiatan pelatihan hidroponik untuk mengatasi keadaan tanah bersalinitas dan lahan terbatas di Gampong Kuala Langsa, Aceh telah terlaksana dengan baik dan lancar. Metode sosialisasi, praktik atau penerapan langsung, dan pendampingan di tahap pemonitoran merupakan tiga tahapan utama yang paling efektif dalam memecahkan persoalan masyarakat di desa tersebut. Manfaat kegiatan yang telah dilaksanakan adalah memberikan pengetahuan dan keterampilan baru kepada masyarakat untuk memanfaatkan lingkungan terbatas dengan kondisi tanah yang memiliki salinitas tinggi tidak mendukung. Kegiatan pengabdian selanjutnya disarankan untuk dikembangkan dan disempurnakan dengan teknologi atau media tanam lain yang ramah lingkungan, relatif murah, dan mudah diperoleh sehingga memberi manfaat yang sama atau lebih.

\section{UCAPAN TERIMA KASIH}

Penulis menyampaikan terima kasih kepada Universitas Samudra atas hibah yang diberikan melalui Program Pengabdian kepada Masyarakat 2018 yang didanai oleh DIPA Universitas Samudra dengan No. Kontrak 698/UN54.6/PM/2018.

\section{REFERENSI}

Bachtiar, S., Rijal, M., \& Safitri, D. (2017). Pengaruh Komposisi Media Hidroponik terhadap Pertumbuhan Tanaman Tomat. Jurnal Biologi Science \& Education, 6(1): 52-60.

Badan Pusat Statistik Kota Langsa. (2010). Langsa dalam Angka 2010. Kerja Sama Badan Pusat Statistik dan Bappeda Kota Langsa.

Badan Pusat Statistik Kota Langsa. (2019). Kota Langsa dalam Angka 2019.

Efriyadi, O. (2018). Pengaruh Perbedaan Jenis Media Tanam Hidroponik terhadap Pertumbuhan Pakcoy (Brassica rapa) dan Kangkung (Ipomea aquatic). The $7^{\text {th }}$ University Research Colloqium 2018. Stikes PKU Muhammad Surakarta.

Fadhli, A. (2011). Statistik Daerah Kecamatan Langsa Barat. Penerbit Badan Pusat Statistik Kota Langsa. Diakses dari https://www.scribd.com/doc/80736702/ StatistikDaerah-Kecamatan-Langsa-Barat-2011

Hendra, H. A. \& Andoko, A. (2014). Bertanam Sayuran Hidroponik ala Paktani Hydrofarm. Jakarta: PT Agro Media Pustaka.

Herwibowo, K. \& Budiana, N. S. (2014). Hidroponik Sayuran untuk Hobi dan Bisnis. Jakarta: Penebar Swadaya.

Kaunang, S. G., Memah, M. Y., \& Kumaat, R. M. (2016). Persepsi Masyarakat terhadap Tanaman 
Hidroponik di Desa Lotta, Kecamatan Pineleng, Kabupaten Minahasa. Agro-sosioekonomi Unsrat, 12(2A): 283-302.

Kota Langsa. (2013). Diakses dari https://www1media.acehprov.go.id/uploads/Kota_Langsa_201 3.pdf

Mardina, V., Fitriani, \& Muslimah. (2019). Sosialisasi Sistem Penanaman Hidroponik Limbah Tebu di Gampong Sidorejo, Langsa, Aceh. Agrokreatif, 5(2): 135-140.

Putri, N. A., Sari, S. M., \& Wondo, D. (2017). Perancangan Interior Restoran dengan Penerapan Self Producing and Consuming Hydroponic Vegetable di Malang. Jurnal Intra, 5(2): 304-312.

Rangian, S. D., Pelealu, J. J., \& Baideng, E. L. (2017). Respon Pertumbuhan Vegetative Tiga Varietas Tanaman Sawi (Brassica juncea L.) pada Kultur Teknik Hidroponik Rakit Apung. Jurnal Mipa Unsrat, 6(1): 26-30.

Roidah, I. S. (2014). Pemanfaatan Lahan dengan Menggunakan Sistem Hidroponik. Jurnal Universitas Tulungagung Bonorowo, 1(2): 43-50.

Satya, A. T., Harjoko, D., \& Ferdyana, W. C. (2017). Pertumbuhan Tomat pada Media Pasir Pantai secara Hidroponik. Jurnal Pertanian UNS 1(1): $281-285$.

Sastro, Y. \& Rokhmah, N. A. (2016). Hidroponik Sayuran di Perkotaan. Jakarta: Balai Pengkajian Teknologi Pertanian.

Surtinah, Nizar, \& Rini. (2017). Pemanfaatan Pekarangan Sempit dengan Hidroponik Sederhana di Pekanbaru. Jurnal Pengabdian kepada Masyarakat (JPKM). 23(2): 274-278.

Syakir, M., Maslahah, N., \& Januwati. M. (2008). Pengaruh Salinitas terhadap Pertumbuhan, Produksi, dan Mutu Sambiloto (Andrographis paniculata Nees). Bul. Littro, XIX(2): 129-137.

Tumangger, B. S. \& Fitriani. (2019). Identifikasi dan Karateristik Jenis Akar Mangrove Berdasarkan Kondisi Tanah dan Salinitas Air Laut di Kuala Langsa. Jurnal Biologica Samudra, 1(1): 9-16.

Zuhaida, L., Ambarwati, E., \& Ningsih, S. (2012). Pertumbuhan dan Hasil Selada (Lactuta sativa L.) Hidroponik Diperkaya Fe. Vegetalika, 1(4): 1321 